\title{
Capacidades estatais para a promoção de processos participativos: atributos do aparato burocrático ou condições temporárias para a ação?
}

\author{
Clóvis Henrique Leite de Souza \\ Doutor em Ciência Política pela Universidade de Brasília \\ Professor no Instituto Federal de Educação, Ciência e Tecnologia de Goiás \\ clovis.souza@ifg.edu.br
}

Resumo Ao propor investigação a respeito das capacidades estatais para a promoção da participação social, o estudo contribui com a compreensão a respeito dos recursos organizacionais necessários à gestão pública participativa, além de investigar sua forma de mobilização. $\mathrm{O}$ foco investigativo está no funcionamento estatal para a organização de conferências nacionais. Assim, revelou a importância de capacidades institucionais, políticas e administrativas, possibilitando a identificação de capacidades técnicas que estão ligadas ao desenho e desenvolvimento de processos participativos. $\mathrm{O}$ artigo propõe a compreensão que capacidades estatais não são, necessariamente, atributos que podem ser instalados em uma estrutura, mas sim condições para a ação, recursos organizacionais que podem ser mobilizados. Assim, permitiu revisar o entendimento de capacidades como atributos de uma estrutura que podem ser gerados ou instalados. Com a investigação empreendida, parece mais razoável falar de capacidades estatais como recursos que podem ser mobilizados a depender das necessidades.

Palavras-chave: capacidades estatais, participação social, conferências nacionais.

\section{Introdução}

Ao transitar em Brasília pela Esplanada dos Ministérios não é dificil encontrar gestoras e gestores traumatizados com processos participativos. $\mathrm{O}$ esforço para sua realização, em muitos casos, abala quem esteve fazendo- 
-os acontecer. Essas pessoas reconhecem boas experiências em suas vivências, como a participação de milhares de cidadãs e cidadãos, o envolvimento de diferentes setores sociais e a elaboração de subsídios para políticas públicas. No entanto, são marcadas por traumas com a contratação de serviços, a operação logística, a articulação interinstitucional, o manejo de conflitos políticos, o desenho e o desenvolvimento de atividades interativas.

Ao entrevistar pessoas que estiveram na preparação e realização de conferências nacionais $^{1}$, foi possível investigar detalhes dos bastidores desses processos participativos. $\mathrm{O}$ interesse era conhecer como tais processos são organizados, na perspectiva de quem os faz acontecer. A intenção foi compreender o funcionamento de agências estatais na promoção da participação social. O foco investigativo estava em identificar o que é necessário à gestão de processos participativos e compreender as formas de mobilização dos recursos utilizados.

Assim, o presente trabalho investiga as capacidades estatais ligadas ao desenho e desenvolvimento de processos participativos. Seguindo o entendimento de Grindle (1996), os recursos organizacionais, sejam eles institucionais, políticos, administrativos ou técnicos, que dão base à ação das agências estatais são aqui compreendidos como capacidades estatais. Ao propor investigação a respeito das capacidades estatais para a promoção da participação social, o estudo contribui com compreensão a respeito dos recursos organizacionais necessários ao funcionamento estatal na gestão pública participativa.

Considerando que a bibliografia especializada em instituições participativas pouco se dedicou às dinâmicas estatais na promoção da participação social, privilegiando a perspectiva social, foi pouco discutida a necessidade de organização do Estado para a interação com a sociedade. $\mathrm{Na}$ análise empreendida, a utilização da chave interpretativa das capacidades estatais facilitou o direcionamento analítico ao funcionamento estatal. Por isso, este trabalho quer contribuir com estudos sobre o funcionamento da gestão pública participativa, destacando a necessidade de organização dos órgãos estatais e mobilização de diferentes recursos para preparar e realizar processos participativos.

Este artigo também propõe revisar o entendimento de capacidades estatais como atributos de uma estrutura que podem ser gerados ou instalados nas distintas unidades administrativas. Com a investigação empreendida, parece mais razoável falar em recursos que podem ser mobilizados, movimentados ou tornados disponíveis a depender das necessidades. Assim, capacidades passam a ser entendidas como recursos para a ação estatal que podem ser mobilizados tanto no Estado como na sociedade, podendo estar disponíveis em certos momentos e posteriormente indisponíveis.

Por isso, a pergunta que orientou a pesquisa foi: Quais são e como são mobilizadas as capacidades estatais necessárias à promoção de processos participativos? Essa questão pressupõe que a promoção da participação na gestão pública demanda organização e, assim,

1 Conferência nacional é um processo convocado por um órgão do Poder Executivo do qual participam representantes da sociedade e do Estado em etapas interconectadas pela formulação de propostas para políticas públicas em uma temática. É uma forma de possibilitar a participação institucionalizada para a gestão de políticas públicas em nível nacional, tendo sido amplamente utilizada no Brasil entre 2003 e 2011 (IPEA, 2013). 
pode ser influenciada pela forma de funcionamento estatal. Além disso, a complexidade da gestão de processos participativos supostamente exige recursos e, por vezes, esses não estão à disposição dos órgãos da Administração Pública responsáveis por tais processos. Assim, a promoção de processos participativos depende da mobilização de recursos organizacionais, sejam eles institucionais, políticos, administrativos ou técnicos, tanto na sociedade como no Estado.

Embora sejam necessárias condições institucionais, políticas e administrativas para a gestão de processos participativos, a pesquisa revelou que elas se assemelham às necessárias em outras ações estatais. Assim, as capacidades estatais específicas à promoção da participação social são recursos técnicos, ou melhor, conhecimentos próprios ao desenho e desenvolvimento de processos participativos. Aqui foram chamadas de capacidades conversacionais, pois influenciam diretamente a forma como as conversas acontecem, ou seja, como as pessoas participantes interagem. São conhecimentos utilizados para gerar soluções adequadas às necessidades de preparação e realização das conferências, saberes práticos que orientam o estabelecimento do propósito, a organização do ambiente, o desenho da metodologia e a mediação do processo.

Além de identificar capacidades estatais necessárias à promoção de processos participativos, a pesquisa que ensejou este artigo teve por objetivo conhecer a forma de mobilização de tais recursos organizacionais. Nesse sentido, a ideia de capacidades estatais como condições de ação e não atributos de uma estrutura pareceu mais adequada com os resultados encontrados. No caso da organização de conferências, ficou explícito que condições institucionais, políticas e administrativas influenciam a mobilização de recursos técnicos para realização de atividades interativas.

$\mathrm{Na}$ realização da pesquisa foram privilegiadas as vozes de pessoas que estiveram em equipes executivas de conferências nacionais, seja atuando na gestão ou em consultorias. Foram realizadas 36 entrevistas com 18 servidoras e 18 prestadores de serviços que integraram equipes responsáveis por conferências em 20 setores de políticas públicas ${ }^{2}$. Para preservar o anonimato das pessoas entrevistadas, estão aqui identificadas apenas com número e área de atuação. Também foram suprimidas as menções a órgãos públicos ou conferências que pudessem gerar identificação dos sujeitos. Além de entrevistas, foram realizadas observações de conferências nacionais ${ }^{3}$ e consultadas fontes documentais como manuais metodológicos e relatórios finais de processos conferenciais com o intuito de compreender com mais detalhes as práticas mencionadas e sua forma de organização.

2 Assistência Social; Comunicação; Cultura; Defesa Civil; Desenvolvimento Regional; Direitos da Criança e do Adolescente; Economia Solidária; Educação; Igualdade Racial; Infantojuvenil pelo Meio Ambiente; Juventude; LGBT; Meio Ambiente; Migrações; Pessoa Idosa; Saúde; Saúde Ambiental; Segurança Alimentar e Nutricional; Segurança Pública e Transparência e Controle Social.

3 O autor esteve presente como observador nas etapas nacionais das seguintes conferências: $2^{\mathrm{a}}$ Defesa Civil; $2^{a}$ Juventude; $3^{a}$ Meio Ambiente; $3^{\text {a }}$ Economia Solidária; $3^{a}$ Mulheres e $14^{a}$ Saúde. Também atuou como consultor na $1^{\mathrm{a}}$ Cultura; $1^{\mathrm{a}}, 2^{\mathrm{a}}$ e $3^{\mathrm{a}}$ Infantojuvenil pelo Meio Ambiente; $1^{\mathrm{a}}$ Saúde Ambiental; $2^{\text {a }}$ Segurança Alimentar e Nutricional; $1^{\text {a }}$ Segurança Pública; e $1^{\text {a }}$ de Transparência e Controle Social. 
Este artigo foi organizado em quatro seções, além desta introdução e das considerações finais. A primeira trata do necessário direcionamento analítico à dimensão estatal quando a intenção é compreender a organização dos processos participativos. Nesse sentido, a segunda seção apresenta as capacidades estatais como categoria útil ao estudo empreendido. $\mathrm{Na}$ sequência, estão expostas ideias referentes às capacidades conversacionais como condições necessárias à promoção da participação. Por fim, é apresentada a forma encontrada para mobilizar tais capacidades na organização de conferências.

\section{Participação social: direcionando o olhar ao funcionamento estatal}

Mesmo que ainda seja comum o debate teórico sobre a viabilidade da participação social na gestão de políticas públicas (Avritzer; Souza, 2013), a institucionalização da participação é uma realidade. A integração de instâncias e mecanismos de participação à estrutura político-institucional gera dever estatal de promovê-los e, assim, necessidade de organização interna e mobilização de recursos para tal tarefa. Assim, uma análise orientada ao funcionamento estatal na promoção de processos participativos pode contribuir com a desnaturalização do pressuposto de que o Estado já está organizado para a interação com a sociedade.

Muitos estudos apontaram impedimentos à efetivação da gestão pública participativa com a observação do funcionamento de processos participativos. Alguns enfatizaram preocupações com a representação na sociedade civil (Lavalle; Houtzager; Castello, 2006) e com a efetividade nas instituições participativas (Pires, 2011), outros se debruçaram sobre variáveis do desenho institucional para perceber diferentes formas de interação entre participantes (Faria, 2007). Ocorreu, inclusive, o adensamento de metodologias para a verificação dos efeitos do incremento da participação social na distribuição de bens públicos (Touchton; Wampler, 2013) ou mesmo o desenvolvimento de indicadores para a construção de um índice de institucionalização da participação (Avritzer, 2010). No entanto, pouco se questiona se a abordagem de pesquisa tem sido capaz de abranger perspectivas de sujeitos sociais e estatais (Pires;Vaz, 2014; Souza; Pires, 2012).

A multiplicação de processos participativos foi acompanhada por um movimento na bibliografia especializada que se voltou para compreendê-los privilegiando a perspectiva de sujeitos ligados a organizações e movimentos sociais. Cabe, portanto, reconhecer a necessidade de um giro analítico que permita também direcionar o olhar para a perspectiva de gestores públicos. Isso pode ajudar a revelar limites e possibilidades da organização dos processos participativos. Reconhecer a dinâmica interna de organização de processos participativos, com base na visão de quem é responsável por seu funcionamento, permite trazer perspectivas que até então foram pouco consideradas e apontar que, para efetivar a participação social na gestão pública, além dos aspectos já considerados, podem também ser necessárias adaptações no aparato estatal.

Quando a bibliografia especializada aborda a perspectiva estatal, concentra-se na noção de vontade política que está entre as condições apontadas para a ocorrência da 
participação institucionalizada na gestão de políticas públicas. Ao lado da densidade associativa e do desenho institucional, o comprometimento de governantes seria variável explicativa para o sucesso de uma instância participativa (Avritzer, 2008). No entanto, vontade política é variável vaga para explicação consistente sobre o bom funcionamento de processos participativos (Souza, 2013), em especial, por ser incapaz de incluir na reflexão um elemento central: a dinâmica organizativa.

Embora escassos, existem alguns estudos que focalizam perspectivas de agentes do Estado, em particular, para a dimensão organizativa dos processos participativos. Forester (1999), por exemplo, ressalta a necessidade de a burocracia se organizar para ouvir as pessoas interessadas e impactadas por ações estatais. Para ele, decidir junto com a população exige habilidades de negociação, escuta e mediação por parte de servidoras públicas. Já Nassuno (2011, p. 16) explicita que a ampliação da participação na gestão de políticas públicas "requer uma forma específica de organização e gestão dos processos e fluxos de trabalho no setor público", concluindo que o modo de funcionamento estatal na gestão pública participativa deve se diferenciar, pois exige distintos recursos organizacionais. Afinal, como enfatiza a autora, não é imediata a compatibilidade entre a lógica de ação do Estado e a participação. Para ela, "iniciativas do setor público que contam com a participação da população exigem do setor público a reorientação de suas estruturas e sistemas, bem como uma postura diferenciada de seus servidores" (Nassuno, 2011, p. 44).

Com a intenção de reconhecer os meios necessários e os disponíveis para enfrentar os desafios organizativos do desenho e desenvolvimento de processos participativos, é plausível que a participação social seja analisada também do ponto de vista de agentes do Estado. Observar a forma de organização de tais processos, sob a ótica de quem os faz acontecer, pode revelar elementos até então pouco estudados. Isso não implica desconsiderar as variáveis já adotadas, isto é, densidade associativa, desenho institucional ou vontade política, mas agregar aspectos organizativos como elementos analíticos, em particular, os recursos para a ação estatal, a saber: capacidades estatais.

\section{Capacidades estatais: condições para a ação estatal}

Ao direcionar o olhar para o funcionamento estatal na promoção de processos participativos, este trabalho utiliza a noção de capacidades estatais. Na maior parte dos estudos que trazem esse conceito, as capacidades estatais são elementos que levam o Estado ao desempenho satisfatório, em especial, na promoção de desenvolvimento. $\mathrm{O}$ foco das investigações, muitas vezes, é conhecer o poder das agências estatais para intervir adequadamente no âmbito socioeconômico a fim de garantir as chamadas transformações estruturais (Evans, 1993; Cotta, 1997).

O interesse se volta ao funcionamento do aparato burocrático diante da necessidade de o Estado assumir papel na regulação da economia e na promoção de ajustes estruturais, assim, a análise é concentrada em condições para a ação estatal no âmbito macroe- 
conômico. Nesse sentido, capacidades estatais estão ligadas ao poder do Estado de levar a cabo sua agenda, com base em um corpo administrativo coerente e qualificado. Assim, as capacidades estatais são atributos do aparato burocrático que demonstra seu desempenho potencial na orientação das ações dos sujeitos (Levitsky; Murillo, 2009).

Evans (1993), por exemplo, pergunta se o Estado é agente transformador ou obstáculo ao desenvolvimento, um problema ou uma solução. Para esse autor, capacidades estatais são elementos que levam o Estado ao desempenho satisfatório na indução, coordenação e regulação de agentes econômicos. O interesse é saber quais são as características de Estados eficazes na promoção do desenvolvimento econômico. A força ou a fraqueza de um Estado, portanto, é perceptível nos atributos institucionais para exercer o controle sobre a sociedade e efetivar escolhas políticas em um território de governo visando ao crescimento da economia.

Nesse sentido, as capacidades estatais são capacidades de governar a sociedade, pois, evidentemente, é nela que estão os agentes econômicos. Um Estado forte é aquele que possui os requisitos para planejar e implementar políticas públicas, embora essa força, muitas vezes, venha justamente das relações com a sociedade, como indica o próprio Evans (1993). Capacidades estatais estão ligadas ao poder do Estado de levar a cabo sua agenda. Por isso, a necessidade do poder sobre a sociedade para regular a ação e forçar os agentes aos comportamentos desejados.

Nessa perspectiva, as capacidades estatais são atributos do aparato burocrático que revela seu desempenho potencial diante da necessidade de orientar a ação dos sujeitos. As capacidades estatais são conectadas à força institucional, ou como dizem Levitsky e Murillo (2009), ao enforcement, que é a capacidade de fazer valer as normas e decisões. As capacidades são expressas nas condições para formular, decidir e executar políticas públicas, em certa medida, independente da interação socioestatal. Esse entendimento faz pensar que o Estado capaz é aquele que consegue executar suas preferências.

Embora alguns autores reconheçam a heterogeneidade do Estado, a relativização da fronteira socioestatal ou mesmo sua relação intrínseca com a sociedade para a suposta formação de preferências, parece prevalecer na bibliografia, como aponta Cotta (1997), uma visão da capacidade estatal ligada à autonomia da burocracia frente às pressões de grupos de interesse. Mazzuca (2012) contribui com o questionamento ao entendimento que, por ventura, restrinja capacidade estatal ao poder para execução de preferências, mesmo que não tenha discutido a complexidade da formação de preferências no Estado. Isso fica explícito quando o autor diferencia autonomia e capacidade.

Para esse autor, autonomia é o poder do Estado de definir, sem interferências, sua agenda. Já capacidade é o poder de realizar essa agenda. A autonomia é uma característica do processo de definição de prioridades e a capacidade um atributo do aparato estatal ligado às condições para viabilizar a agenda política. Autonomia e capacidade não necessariamente andam juntas, por isso Mazzuca (2012) insiste em diferenciá-las. Segundo ele, "podem existir Estados autônomos, mas sem capacidade de execução das ações e também 
Estados capazes de executar políticas públicas, mas que a definição de objetivos fica por conta de certos grupos poderosos" (Mazzuca, 2012, p. 547).

O propósito de desagregar autonomia e capacidade é obtenção de precisão empírica, pois, como diz Mazzuca (2012), a rigor, ambas são partes do conceito de poder estatal. De todo modo, o autor alerta que seria restritivo atribuir capacidade ao aparato burocrático administrativo do Estado e autonomia à direção política do governo. Tal diferenciação facilita a compreensão do que sejam as capacidades estatais, mas acaba por desconsiderar que as condições tanto para a definição quanto para a realização de políticas se constituem nas relações do Estado com a sociedade. Assim, ganha força o entendimento de capacidades estatais como condições para a ação do Estado e não apenas atributos de uma estrutura organizacional com corpo de funcionários capacitados e coerência normativa.

Tal diferenciação facilita a compreensão do que sejam as capacidades estatais, o entendimento de capacidades estatais como condições para a ação do Estado ganhando força e não apenas atributos de uma estrutura organizacional como a existência de um corpo de funcionários com coerência normativa e corporativa. Assim, não é cabível limitar as capacidades a características ou atributos de um corpo administrativo. $\mathrm{O}$ entendimento neste trabalho é que capacidade estatal é aquilo que o Estado mobiliza para viabilizar sua atividade, ou seja, condições para a ação estatal, circunstâncias ou recursos organizacionais que favorecem o agir, ou seja, requisitos para a ação efetiva.

O olhar para as capacidades estatais pode ser direcionado a fatores que favorecem atividades do Estado voltadas à garantia da paz, do crescimento econômico, do bem-estar da população e, porque não, da democracia. Assim, cabe também conhecer o que a bibliografia diz a respeito das capacidades estatais que potencializam a democracia, em particular, no que tange às formas interativas de relações socioestatais para a gestão de políticas públicas. De início, a noção de poder infraestrutural do Estado (Mann, 1993) ajuda no entendimento das capacidades estatais, pois há um aspecto explicitamente relacional nessa ideia.

Soifer e Hau (2008), ao apresentarem as ideias de Mann (1993) sobre o poder infraestrutural do Estado, possibilitam o entendimento que tal poder seria o mesmo que capacidades estatais. O poder infraestrutural estaria nas condições para o Estado desenvolver seus projetos de maneira coordenada com organizações territorialmente localizadas e também nas conexões organizacionais que potencializam tais capacidades. Para os autores, não são apenas as atividades administrativas que possibilitam as ações do Estado, mas, em especial, as conexões entre os agentes estatais e não estatais. Portanto, nas capacidades estatais estariam as condições internas de ação (recursos disponíveis e modo de organização da burocracia), além dos arranjos institucionais que possibilitam as interações socioestatais.

Importante alertar que para Soifer e Hau (2008), seguindo Mann (1993), capacidade é o poder de implementar políticas públicas e controlar o território, podendo ser feito com ou sem a sociedade. Da leitura de Mann (1993), depreende-se que capacidades podem ser criadas de muitas maneiras, nem todas democráticas. A capacidade pode ser obtida, inclusive, com repressão à sociedade para efetivar políticas e controlar territórios. No entanto, com a noção de poder infraestrutural, esses autores indicam que a relação com a sociedade 
pode aumentar o poder de implementar políticas públicas. Argumentam que quando isso acontece, o poder da sociedade também aumenta, explicitando o caráter relacional das capacidades estatais já apontado por Evans (1993) com a noção de autonomia inserida.

Também com a perspectiva relacional, outra parte da bibliografia compreende capacidade estatal incluindo as interações socioestatais explicitamente em contextos democráticos. Um Estado capaz é aquele que tem condições de mediar as demandas para executar as políticas delas derivadas. Contribui com esse entendimento a visão de Grindle (1996, p. 7) em que o Estado capaz é aquele que tem condições de "ser responsivo às demandas e pressões de grupos da sociedade e de ser hábil para mediar demandas sociais e manter instituições que são efetivas na resolução de conflitos".

Esse entendimento abre espaço para uma compreensão multidimensional das capacidades estatais, pois ali estão componentes de mediação de demandas e conflitos sociais, bem como de efetividade das instituições. Além disso, quando a autora traz a noção de responsividade, possibilita afirmar que o funcionamento de processos participativos está entre as condições para a ação do Estado. Assim, as capacidades são condições para formular, decidir e executar políticas públicas, mas não de maneira independente da sociedade. As capacidades são recursos disponíveis para a ação, são condições de ação do Estado, circunstâncias que levam o Estado ao efetivo desempenho, mas isso sempre em conexão com a sociedade.

A noção de capacidades estatais como condições para a ação estatal em conexão com a sociedade permite pensá-las em quatro dimensões: institucional, política, administrativa e técnica. Essa ideia vem a partir da perspectiva multidimensional de Grindle (1996) que compreende capacidades estatais nesses quatro aspectos. O interesse da autora era levantar hipóteses para sua pesquisa sobre a crise dos anos 80 e 90 na América Latina e África. No entanto, seu entendimento sobre capacidades estatais foi inspirador para a compreensão aqui desenvolvida. A perspectiva multidimensional não resolve e até agrava a ardilosa confusão gerada pela bibliografia a respeito de capacidades estatais.

Há lugares, como neste artigo, em que capacidade se assemelha a um insumo para um processo, ou como aqui é dito: condição para a ação estatal. Em outras visões, capacidade é um resultado de um processo, como o poder de executar uma ação. No primeiro entendimento, Estado capaz é aquele que tem recursos adequados para o alcance de um objetivo. Na segunda compreensão, Estado capaz é aquele que alcança o objetivo. E não se trata apenas do momento em que se fala (antes ou depois da ação), mas da capacidade como entrada (input) ou como saída (output) do processo estatal.

Capacidade estatal é aqui entendida como condição (input, entrada ou insumo) de um processo estatal e não como resultado (output, saída ou produto) do processo estatal. Capacidades estatais são recursos institucionais, políticos, administrativos e técnicos que dão base para uma ação do Estado. Diante da complexidade da própria organização estatal e de suas relações com a sociedade, as ideias de Grindle (1996) inspiram uma compreensão multidimensional das condições de ação do Estado.

Reconhecendo as quatro dimensões das capacidades estatais é possível diferenciar condições de legitimidade (institucionais), de relacionamento (políticas), de operação 
(administrativas) e de conhecimento (técnicas) para a ação estatal. Nesse entendimento multidimensional, a coerência corporativa (critérios meritocráticos no recrutamento e na progressão funcional), a concentração de conhecimentos e habilidades em um corpo administrativo (burocracia qualificada) e o enforcement (poder de fazer cumprir regras e executar políticas) seriam alguns dos aspectos das capacidades estatais e não a totalidade, quando vistos de forma integrada e não isolada. Por isso, insistir que, ao pensar a promoção de processos participativos, é útil compreender capacidades estatais como condições para ação estatal (input, entrada ou insumo). Capacidades estatais são recursos institucionais, políticos, administrativos e técnicos que dão base para uma ação do Estado.

Vale a distinção de cada um dos âmbitos, pois isso não restringe a noção de capacidades a atributos do aparato burocrático, desconsiderando as relações socioestatais. Caem por terra entendimentos que defendem a constituição de agências estatais insuladas e capazes quando podem bloquear influências sociais. Os trabalhos de Pereira (2014) e de Gomide e Pires (2014) também diferenciam dimensões nas capacidades estatais. No entanto, quando falam de aspectos relativos aos processos participativos, os tratam de maneira ampla, sem o aprofundamento às especificidades de seu funcionamento.

Gomide e Pires (2014), ao estudarem arranjos político-institucionais de políticas públicas, dizem que tais arranjos dotam o Estado de capacidades de implementação técnico-administrativas e políticas. Entre as capacidades políticas, os autores investigam as formas de interação da burocracia do Executivo com agentes do sistema político-representativo, a existência de instâncias de participação social e a atuação de órgãos de controle. Concluem que o desenvolvimento de processos participativos na gestão pública, ao lado de contatos com agentes do sistema representativo, exerce "papel importante na promoção de inovações ao longo da implementação dos programas e projetos" (Gomide; Pires, 2014, p. 374). De toda forma, não falam de capacidades para a promoção da participação social e sim da participação como elemento da constituição de capacidades estatais.

Já Pereira (2014), ao estudar a construção de capacidades por meio da interação entre agências estatais e também agentes sociais e econômicos, fala em capacidades relacionais especificando-as em capacidades participativas, decisórias e de coordenação interburocrática. A autora indica que as capacidades participativas seriam as "habilidades das burocracias estatais criarem canais de diálogo efetivos com os grupos sociais afetados por determinada política" (Pereira, 2014, p. 54). Esse entendimento se aproxima do desenvolvido no presente trabalho, porém também não adentra no detalhamento das capacidades para a gestão de processos participativos.

Ambos os estudos (Gomide; Pires, 2014; Pereira, 2014) tratam das relações socioestatais como parte das capacidades estatais, convergindo com a visão aqui empreendida. A contribuição deste trabalho é conhecer as condições específicas para que o Estado promova a participação social; por isso, a defesa da noção de capacidades estatais em quatro dimensões. Essa compreensão não trata exclusivamente de elementos do modo de organização e funcionamento da burocracia. Ou melhor, não restringe as condições para ação do Estado na interação socioestatal de qualidade aos arranjos burocráticos. Assim, também 
ao pensar a promoção de processos participativos, é útil compreender capacidades estatais como condições para ação estatal, englobando recursos institucionais, políticos, administrativos e técnicos.

Entre as quatro dimensões das capacidades estatais, a institucional traz as normas que organizam a participação social na gestão pública. Nela está contido o conjunto de regras que orientam o funcionamento dos processos participativos. A capacidade institucional é a condição de estabelecer os parâmetros para o desenvolvimento do processo participativo de maneira adequada à realidade organizacional da agência estatal promotora do processo e do campo político dos sujeitos participantes. A adequação e o cumprimento do estabelecido em regimentos, regulamentos e outros atos normativos dos processos participativos podem revelar capacidades na dimensão institucional.

A dimensão política aponta para a incorporação dos processos participativos à forma de tomada de decisões no Estado. Traz a conexão dos processos participativos ao ciclo de gestão de políticas públicas e a outras formas de interação socioestatal. É conhecida a dificuldade de coordenação de políticas públicas, por isso a integração de diferentes órgãos públicos e instituições participativas no processo de interação socioestatal pode ser um exemplo da dimensão política das capacidades estatais. As capacidades políticas apontam para as condições de mobilizar os recursos necessários ao funcionamento e desencadear os encaminhamentos necessários à gestão do processo participativo.

A dimensão administrativa fala das capacidades para realizar procedimentos necessários ao funcionamento dos processos participativos. O olhar é para as condições de operação do Estado na promoção da participação social na gestão de políticas públicas. As agências estatais necessitam de um modo de organização adequado às características dos processos participativos e condizentes com os princípios e regras da Administração Pública.A compatibilidade dos procedimentos administrativos com o funcionamento dos processos participativos e a disponibilidade das condições materiais (recursos materiais e financeiros) para a promoção da participação social são exemplos das condições de operação da organização estatal na dimensão administrativa.

A dimensão técnica trata da mobilização de recursos cognitivos para gerar soluções adequadas aos processos participativos, em particular, promover condições para interações qualificadas em conversas direcionadas a um propósito. Importam os conhecimentos e as habilidades do corpo técnico para a formulação de propostas compatíveis com as necessidades específicas da interação socioestatal para a gestão de políticas públicas. A construção de soluções técnicas adequadas se dá quando são considerados os propósitos declarados, o público potencialmente participante e os recursos disponíveis para o processo participativo.

A compreensão das capacidades estatais como condições de ação permite pensar, de maneira mais complexa, sobre distintas dimensões dos recursos organizacionais necessários à interação socioestatal. Mesmo que do ponto de vista institucional, político e administrativo haja inúmeras necessidades para o funcionamento de processos participativos, como será demonstrado, é na dimensão técnica das capacidades estatais que se encontram os conhecimentos próprios ao seu desenho e desenvolvimento. 


\section{Capacidades conversacionais: dimensão técnica da promoção da participação social}

O desconhecimento técnico-metodológico para o desenho e desenvolvimento de processos participativos provoca a gestão inadequada ou ineficiente de tais processos. $\mathrm{Na}$ pesquisa, foi possível perceber que a promoção da participação é impactada por condições institucionais, políticas e administrativas. No entanto, são aspectos técnicos que influenciam diretamente o modo de interação entre as pessoas participantes.

Afinal, os recursos institucionais, políticos e administrativos que dão base para a promoção da participação social na gestão pública são muito semelhantes aos necessários em outros contextos de ação estatal. Mesmo que em cada área de política pública haja especificidades pelo histórico de constituição e pelos sujeitos envolvidos, as condições que trazem legitimidade (institucionais), potencializam o relacionamento (políticas) e promovem a operação (administrativas) das agências estatais se assemelham. Não é muito diferente entre as áreas, embora com objetos distintos, fazer as relações institucionais, políticas ou gerar as condições administrativas. É no campo técnico (conhecimento específico) que estarão as distinções. No caso, as técnicas para a organização da interação socioestatal são singulares, mesmo que compartilhadas em distintas áreas de política, pois decorrem de conhecimentos ligados ao campo do desenho e desenvolvimento de processos participativos. O saber técnico é distinto para a promoção da participação, mas são saberes práticos indispensáveis à realização de atividades interativas em qualquer área.

Conhecimentos práticos são necessários para garantir que estrutura, estímulos e mediação da conversa sejam adequados ao propósito e contexto da interação. Não basta reunir pessoas interessadas em temas comuns para que a participação aconteça com qualidade, é preciso ter condições de ação e saber fazer para que haja oportunidade para a interação efetiva. Assim, analisar as capacidades técnicas para a promoção de processos participativos pode qualificá-los, tendo em vista a potência do aporte de práticas e técnicas de interação conversacional.

Em processos com grande quantidade de participantes, como são as conferências nacionais, as capacidades conversacionais se expressam em soluções para a interação, definindo a forma como será abordada a pauta e a maneira como interesses e divergências serão apresentadas. Elas condicionam o estímulo à conversa, o ordenamento das falas, o modo de registro, a visualização das ideias coletivas, a organização do ambiente, o tempo para a interação e a mediação dos fluxos conversacionais.

A partir das entrevistas realizadas com integrantes de equipes executivas de conferências, foi possível perceber que as capacidades conversacionais podem ser compreendidas em quatro âmbitos: 1) Estabelecimento do propósito - guia o processo e indica a pertinência e adequação das escolhas operacionais e metodológicas, além disso, permite a identificação de possíveis participantes e resultados esperados; 2) Organização do ambiente - condições materiais e organizativas que criam a atmosfera e materializam o contexto da conversa, influenciando a disposição das pessoas para a interação; 3) Desenho da meto- 
dologia - modo de proceder que estimula interações direcionadas e estrutura a conversa, orientando a ordem, o tempo e a forma de expressão; e 4) Mediação do processo - apoio metodológico que orienta o fluxo conversacional, enfatizando a estrutura da conversa diante da dinâmica do grupo de participantes.

Estabelecer o propósito de um processo participativo é a primeira condição para a ação estatal na promoção da participação social, pois a intenção é o que guiará quem organiza e quem participa. Com a delimitação do propósito é possível avaliar a adequação da convocação do processo, desenhar suas atividades e avaliar seus resultados. Definidas as intenções da conversa, a preparação do processo pode ser iniciada. Ao estabelecer o propósito, devem estar claros os resultados esperados e os potenciais participantes, o que possibilita a organização do ambiente e o desenho da metodologia para a interação.

Nas conferências, o estabelecimento do propósito é feito com a convocação do processo que se dá por decreto presidencial, portaria ministerial, portaria interministerial ou resolução de conselho. A definição dos objetivos da conferência pode ser elencada entre os desafios institucionais para a organização de conferências, pois a formulação de diretrizes para o processo participativo compõe capacidades estatais na dimensão institucional. Além disso, é no âmbito político que se dá a negociação com os diferentes sujeitos envolvidos para o estabelecimento do propósito coerente com expectativas e interesses. De toda forma, mesmo dependente de capacidades institucionais e políticas, tal ação é vista aqui como capacidade técnica, pois direciona a organização do ambiente, o desenho da metodologia e a mediação do processo participativo.

Nas conferências parece que a dificuldade de estabelecimento do propósito não ocorre apenas entre participantes, mas também entre quem é responsável pela realização do processo, isto é, seus organizadores. Há entre as entrevistadas a compreensão da importância da definição de objetivos para a preparação e desenvolvimento das atividades. Quem organiza uma conferência, deve ter clareza de propósito para que o processo não se esvaia em um encontro sem objetivos e resultados alcançados. A "clareza do que tem que ser feito, dos objetivos de cada momento" (Entrevista 6 - Gestão, 2014), leia-se a delimitação do propósito, é importante para a avaliação da pertinência e adequação da convocação do processo, para o desenho da metodologia da conversa e para a análise da efetividade de uma conferência. Afinal, como em qualquer ação pública, a motivação e a intenção orientam a organização de processos participativos. Parece inócuo o desenvolvimento de processos participativos sem que sejam negociadas e estejam explicitadas suas finalidades (Brown; Isaacs, 2007).

Estabelecido o propósito, elemento central para a preparação da atividade é a organização do ambiente que receberá as pessoas participantes. Embora a organização do ambiente seja tarefa supostamente ligada às capacidades administrativas, pela necessidade de recursos materiais e financeiros que dão base à ação, aqui é defendida a ideia que nela há especificidades técnicas. A operação administrativa é comum a outras ações do Estado, mas o que é específico às capacidades estatais para a promoção da participação são os conhecimentos relacionados aos requisitos técnicos da organização do ambiente. São 
saberes práticos que contribuem para a criação de atmosfera propícia à interação, pois é reconhecida a influência do ambiente nas conversas (Moscovici; Doise, 1991).

Em atividades com grande quantidade de participantes, como são as conferências nacionais, a complexidade logística exige dedicação e esforço das equipes organizadoras. Entre as pessoas entrevistadas, a criação da atmosfera para a interação entre participantes, aparece entre as preocupações quando pensam em questões como ruído e desconforto térmico, além da disposição física das cadeiras. A fala da entrevistada a seguir reconhece a importância do ambiente para a qualidade da interação.

Sempre tem esse problema de sala, quando você tem muitas pessoas e muitas salas para montar, várias salas acabam sendo improvisadas. Nesse improviso, as pessoas só pensam em colocar tantas pessoas dentro dessas salas. Parece até que as pessoas não precisam ser escutadas, não precisam se ver, não precisam ter ar e nem circular pelo espaço, não precisa nada, só precisa estar dentro da sala. Nessas coisas de logística as pessoas têm dificuldade de entender que o ambiente interfere na interação. (Entrevista 5 - Consultoria, 2014).

Ao falar do "problema de sala", a entrevistada indica que "o ambiente interfere na interação". E parece que há uma dificuldade de entendimento sobre essa interferência por parte de quem cuida da operação logística dos eventos. Não se trata da inexistência de recursos materiais, mas da organização adequada deles diante dos requisitos das atividades propostas. Quando ironiza as circunstâncias de salas "improvisadas", a entrevistada parece confirmar que o estado de ânimo de um grupo tem grande relação com o espaço disponível para o trabalho (Moscovici; Doise, 1991).

A forma de organizar a interação diante de um propósito, em um ambiente particular, estrutura uma conversa. É a metodologia que estabelece a agenda de trabalho, os momentos, o fluxo e o ritmo das atividades. O desenho da metodologia é o plano sobre como proceder na conversa para estimular interações direcionadas ao propósito. Afinal, estabelecido o propósito e organizado o ambiente, as interações tendem a ocorrer espontaneamente. No entanto, para manter o foco das conversas é necessário desenhar a metodologia adequada ao propósito e que considere o grupo participante.

Em conferências nacionais, o mais comum é a utilização da assembleia como estrutura para as conversas, seja em grupos de trabalho ou plenárias. Mesmo que a assembleia seja o padrão de estrutura conversacional em conferências, as pessoas entrevistadas apontaram algumas inovações metodológicas, com destaque para o trabalho em subgrupos, a forma de priorização e também os momentos interativos. A entrevistada abaixo aponta que inovações simples foram capazes de alterar padrões de interação e fazer com que "as pessoas enxergassem o processo de conversar de um jeito diferente".

E o que era que a gente estava propondo? Era uma metodologia muito simples, por exemplo, dividir em subgrupos ou fazer priorização. Esse tipo de inovação fazia com que as pessoas enxergassem o processo de conversar de um jeito diferente porque elas podiam falar. É diferente você falar num grupo de cinquenta ou num grupo de sete pessoas e aquilo se encaixar no 
processo. (Entrevista 3 - Consultoria, 2014).

O desenho metodológico das conversas responderá aos propósitos delineados para as atividades participativas: compartilhamento de conhecimento, geração de ideias, criação de relações, ação colaborativa, engajamento no conflito ou decisão coletiva. Isso não significa forçar o grupo de participantes a agir de uma determinada forma, mas sim orientá-lo. Mesmo que haja um padrão comunicacional em um determinado contexto, se um propósito é estabelecido, pode ser pensada uma metodologia com estímulos para atingi-lo. As metodologias funcionam como uma estrutura ou arquitetura para a interação, pois organizam o modo de estar na conversa. São fases, etapas ou passos de um movimento proposto para as pessoas participantes (Bojer et al., 2010).

Por fim, cabe tratar da mediação do processo como uma capacidade conversacional. Afinal, se a intenção é manter o foco das conversas, de nada adianta desenhar a metodologia se não houver mediação adequada do fluxo conversacional. Por isso, é determinante a atuação de mediadores que orientam as interações com foco nos resultados esperados e garantem a estrutura operacional para a realização das atividades, sem descuidar da dinâmica do grupo participante. Para tal, quem se dedica à mediação de conversas necessita de forte habilidade de escuta e leitura da dinâmica grupal, além do domínio de técnicas para o estímulo à interação.

O papel de mediação é aquele desempenhado por pessoas que desenham e desenvolvem o processo participativo, sendo central em processos participativos com grande quantidade de participantes como são as conferencias nacionais. Orientada pelos propósitos e resultados esperados, a mediação é guia no fluxo conversacional. É ela que dá as direções do processo a ser desenvolvido pelo grupo de participantes. Cabe a quem faz a mediação estruturar a conversa, estimulando a interação focada nos propósitos e resultados esperados. A principal tarefa da mediação é, portanto, o apoio metodológico ao grupo. Isso implica desenhar e desenvolver a metodologia, sem descuidar da organização do ambiente necessário para viabilizá-la.

As entrevistadas sinalizam que a preocupação na mediação em processos participativos como conferências é promover conversas que gerem resultados. O desafio é saber estruturar e manter uma conversa em grupo, gerando espaços para que cada sujeito possa apresentar seus pontos de vista, mas, em particular, condições para ouvir os outros e convergir em questões comuns. Para tal, são necessárias pessoas na mediação que tenham à disposição técnicas e habilidades que possibilitem nível distinto de entendimento e compreensão entre diferentes sujeitos, trazendo à tona pressupostos e permitindo a compreensão e a mudança de posições (Baker; Fraser, 2005).

Pela pesquisa realizada, foi possível constatar a existência de conhecimentos aplicados que possibilitam a preparação e a realização de atividades efetivamente interativas no contexto da gestão participativa. Chamadas de capacidades conversacionais, pela influência na interação conversacional dos sujeitos participantes de processos participativos, esses saberes práticos foram aqui identificados e organizados em quatro âmbitos: estabe- 
lecimento do propósito, organização do ambiente, desenho da metodologia e mediação do processo. Esse conjunto de conhecimentos ganha relevância, pois orienta a forma de interação nas conversas.

\section{Mobilização de capacidades estatais para a promoção de processos participativos}

As capacidades conversacionais são acionadas dependendo do contexto institucional, político, administrativo e técnico que as demandaram. É possível dizer que sofrem influência de condições técnicas, administrativas, políticas e institucionais do órgão promotor do processo participativo, mesmo que esta pesquisa não forneça dados sobre o poder de influência, ou melhor, sobre o grau desse influxo. Como indica a entrevistada abaixo, as metodologias nunca eram uma aplicação automática, mas sempre adaptadas à realidade de sua aplicação.

Conforme fomos avançando e mostrando resultados, a gente foi incrementando as inovações e raramente a gente pegava e reaplicava exatamente uma metodologia de fora. Porque elas não eram replicáveis, eram ajustáveis, adequáveis à realidade do cliente. Foi assim também que a gente acabou criando muitas ferramentas. Dependia do espaço político e da infraestrutura disponível, porque essas variáveis dizem quais metodologias podem ser utilizadas. Assim, a forma como se construía a metodologia era adequada àquele contexto específico, para aqueles atores, para aquele tema, para os recursos que estavam disponíveis. Era quase um trabalho artesanal. (Entrevista 3 Consultoria, 2014).

O "trabalho artesanal" era justamente desenhar uma metodologia "adequada àquele contexto específico". Isso significava considerar os atores envolvidos, o tema em questão e os recursos disponíveis. A fala evidencia a ideia das capacidades gerais (administrativas, políticas e institucionais) influenciando a capacidade técnica específica (capacidade conversacional), pois diz que a criação de ferramentas metodológicas "dependia do espaço político e da infraestrutura disponível". É possível dizer que eram as condições institucionais, políticas e administrativas que indicavam o espaço disponível para a ação técnica que disseminava uma inovação metodológica. Nesse sentido, mesmo que a metodologia fosse adaptada a cada realidade de aplicação, havia elementos comuns entre as aplicações.

Como visto, para algumas entrevistadas não parecia adequado reaplicar instantaneamente as metodologias, mesmo que fossem adaptadas e incrementadas a partir de experiências anteriores em conferências nacionais. Aliás, foi o aprendizado com a experiência, além da circulação de pessoas e dos espaços de intercâmbio, que fizeram acontecer a disseminação de novas práticas metodológicas para o desenho e desenvolvimento desses processos participativos. Aprendizado obtido por aquelas pessoas que integraram equipes de organização de conferências. Mesmo que tenham acesso a registros de conferências anteriores, parece que a vivência prévia é o que permite "perceber o que 
deu certo e o que não deu" (Entrevista 17 - Consultoria, 2014). Essa também é a visão de outra entrevistada quando fala que sua trajetória permitia antever dificuldades e agir para minimizar os impactos.

Eu percebia alguns erros que iam acontecer na metodologia previamente. Porque eu estava ligado nas coisas. Eu acho que a gente vai acumulando experiência, porque fazer evento desse porte não é fácil. Aí você vai, no aprendizado, desenvolvendo outras expertises mesmo, fica mais safo para determinadas coisas. A velocidade com que esses eventos acontecem, faz com que a gente precise ter outra postura, que é uma postura proativa e que antecipa a solução dos problemas. (Entrevista 5 - Consultoria, 2014).

O que fica evidente é que a experiência prévia possibilita o desenvolvimento de "expertises" para trabalhar em eventos desse "porte" e com essa "velocidade". Há o reconhecimento do trabalho em conferências como atividade com características que exigem habilidades específicas, sendo que o aprendizado é acumulado e levado para outras conferências. É a circulação de pessoas em diferentes conferências que faz a disseminação de soluções e novas práticas.

Foi possível perceber nesta pesquisa que um mesmo grupo de consultores, atuando como profissionais autônomos ou como empresa, foi responsável pela implantação e disseminação de soluções metodológicas que materializara capacidades estatais em cada caso. Conectados entre si, indicaram trabalhos uns para os outros e atuaram em conjunto, compartilhando experiências, ao ponto de contribuírem com a qualificação de profissionais que atuavam em conferências há menos tempo. Pelas soluções aportadas, passaram a ser reconhecidos e convidados à atuação em outros processos, levaram as novas práticas, adaptando às realidades encontradas, como indica a entrevistada a seguir.

Como eu estava mais envolvido com o tema, você acaba conhecendo pessoas na esplanada, em reuniões. Aí quando termina uma conferência, o pessoal já te chama para outra. Ou até durante, já dizem 'a gente está pensando ano que vem fazer a conferência X, vamos conversar'. Aí troca cartão etc. Aconteceu comigo, numa etapa nacional estava lá o coordenador de outra conferência, vivenciando o momento interativo. Então ele viu o troço e falou 'muito legal e tal' e me chamou para trabalhar. (Entrevista 4 - Consultoria, 2014).

Como estruturas temporárias, as equipes executavam os projetos, aportando condições técnicas e, findo o período de contratação, levavam consigo os conhecimentos práticos produzidos. As soluções metodológicas foram disseminadas justamente pela circulação dessas pessoas que sabiam fazer, ou seja, detinham o conhecimento prático para a organização de conferências. Isso explicita que os conhecimentos para fazer acontecer uma conferência, no que tange ao estabelecimento do propósito, organização do ambiente, desenho da metodologia e mediação do processo, nem sempre estavam instalados e disponíveis no Estado. A contratação de consultorias no processo de organização de conferências foi uma maneira de mobilizar capacidades estatais para a promoção da 
participação, garantindo as condições técnicas, ou seja, os recursos cognitivos e humanos necessários para a preparação e a realização de conferências nacionais.

A mobilização, fora do Estado, de conhecimentos práticos para a gestão de processos participativos foi a forma de dotá-lo de recursos organizacionais para a ação, em especial em áreas como metodologia das conversas, sistematização das propostas, mobilização de participantes, logística de eventos e comunicação social. Aparentemente, a indisponibilidade no Estado de corpo técnico habilitado para o desenho e desenvolvimento de processos participativos deu margem à contratação de prestadores de serviço. Isso constituiu o meio para mobilizar capacidades estatais necessárias à realização de conferências.

É bem verdade que conferências históricas pareceram recorrer menos às consultorias para a execução das atividades. Nas entrevistas com integrantes das equipes de gestão dessas conferências, as secretarias executivas dos respectivos conselhos nacionais foram apontadas como fundantes para a execução das atividades dos processos conferenciais. A fala de uma entrevistada é explícita: "Temos uma boa secretaria executiva no Conselho que no dia seguinte que termina a conferência, a gente já pede o local da próxima conferência, para você ter uma ideia, e já começa a pensar em algumas situações relacionadas ao próximo processo" (Entrevista 16 - Gestão, 2014). De toda forma, a contratação de consultorias não é descartada nesses órgãos, mas utilizada em questões muito pontuais como estudos e pesquisas e não na operação metodológica das conferências.

No entanto, alguns órgãos neófitos em processos conferenciais ou sem pessoal disponível e capacitado, acabaram por lançar mão da atuação de prestadores de serviço para complementar sua capacidade de ação. Devido à indisponibilidade de pessoal, alguns órgãos contaram com consultorias de toda a ordem para a realização das conferências. Afinal, como comentou uma entrevistada, um projeto do porte de uma conferência

precisa de gente. E o que acontece é que muitas vezes o próprio ministério não tem equipe. Não tem servidor no quadro. Então é necessário um termo de referência para contratar consultores, porque não há uma equipe. E quando há uma equipe interna ao ministério, ela está envolvida com tantas outras questões que o próprio serviço público exige, para além da conferência, que não permite a necessária dedicação exclusiva. (Entrevista 6 - Gestão, 2014).

Assim, muitas vezes a equipe contratada para consultorias atua como equipe base do órgão. A prática de contratação de consultorias para suprir escassez de pessoal pareceu recorrente no contexto de realização das conferências. As trocas entre equipes de gestão de diferentes ministérios acabaram por gerar apropriação de conhecimentos e disseminação de soluções para os desafios organizativos. Como visto, perguntadas sobre como chegaram aos trabalhos de consultoria que desenvolveram em conferências, as pessoas disseram que os seus serviços eram indicados de um ministério para o outro. A entrevistada a seguir menciona contatos institucionais como forma de aprendizado prático e também para a contratação de prestadores de serviço para o desenho e desenvolvimento da metodologia apropriada ao contexto da conferência. 
A Conferência respirou muito da experiência dos próprios consultores e de outros processos participativos. Me lembro de duas conferências mais recentes que utilizaram conferências livres e que tomamos como referências. Navegamos no site para ver como estavam sendo usadas e como as informações foram divulgadas. Além disso, conversamos com outras coordenações de conferência para ver os problemas enfrentados com logística. Recebemos uns toques, indicações de consultorias e tentamos evitar gargalos. Mas eu diria que, assim, a metodologia se valeu muito mais da bagagem dessas pessoas que desenvolveram ela. A metodologia, de fato, foi desenvolvida pelos consultores. O órgão demandou um modelo e esse modelo foi desenvolvido, com base na encomenda. (Entrevista 13 - Gestão, 2014).

Além de reuniões bilaterais, foi indicado, por algumas pessoas entrevistadas, que as atividades promovidas pela Secretaria Geral da Presidência da República foram espaços de intercâmbio. Em particular, reuniões ocorridas no âmbito do Fórum Governamental de Participação Social, que reuniam representantes de ouvidorias, secretarias executivas de conselhos e comissões organizadoras de conferências para debate e troca de experiências. Esses eram espaços onde as pessoas trocavam informações a respeito de soluções para problemas de organização de conferências. A partir de relatos sobre desafios enfrentados por outras conferências, as coordenações tentavam alternativas. Isso parece ter ocorrido em diferentes âmbitos, inclusive na área de metodologia das conversas. Houve menções também a reuniões específicas com a equipe da Secretaria Geral que comentava sobre boas práticas já realizadas em outros processos.

A presença de prestadoras de serviços contribuiu com a mobilização de capacidades conversacionais. Esses profissionais envolvidos em equipes executivas de conferências deram condições ao desenho e desenvolvimento de parte desses processos participativos. A circulação de pessoas que aprenderam com a experiência e em espaços de intercâmbio impulsionou a adoção de soluções similares em diferentes processos e foi capaz de mobilizar as capacidades estatais para a preparação e a realização de conferências nacionais. Essa dinâmica de aprendizagem e aplicação reforça a existência de um conjunto de conhecimentos e saberes práticos não instalados, mas mobilizados pelo Estado para os processos participativos.

\section{Considerações finais}

Foi o saber prático, acumulado a partir do aprendizado com experiências de desenho e desenvolvimento de processos participativos que possibilitou a mobilização de capacidades conversacionais para a realização de conferências, em particular, no que diz respeito ao estabelecimento do propósito, organização do ambiente, desenho da metodologia e mediação do processo. Portanto, é possível dizer que, além dos espaços de intercâmbio, foi a circulação de pessoas, com vivências similares a respeito da gestão de conversas com grande quantidade de participantes, que possibilitou a mobilização das capacidades conversacionais. Como estruturas temporárias, as equipes executavam os projetos, aportando condições técnicas e, findo o período de contratação, levavam consigo os conhecimentos práticos produzidos. 
Isso contradiz a noção de capacidades estatais como atributos do aparato burocrático (Levitsky; Murillo, 2009) e do corpo funcional perene e qualificado (Evans, 1993) como requisito da existência de capacidades técnicas. Afinal, muitas pessoas que trabalharam em processos de organização de conferências e que dotaram o Estado de capacidades conversacionais eram prestadoras de serviço com vínculos temporários. Mais coerente com a realidade encontrada nas conferências é falar em capacidades como condições de ação que podem existir em um momento e depois não mais existir. São recursos que uma organização mobiliza em um determinado momento para certa finalidade e que, posteriormente, podem não estar mais disponíveis.

A existência temporária de capacidades estatais que podem deixar de existir em outras circunstâncias não precisa ser vista como um demérito. Pelo contrário, pode ser mais adequado ao Estado ter condições de ação sem que isso implique em instalar e realizar a manutenção dos recursos. Conhecer a insuficiência de capacidade instalada para que possa ser mobilizada conforme a necessidade é por si só uma capacidade. Isso implica ter condições de mapear as demandas de recursos e as oportunidades de oferta para assim mobilizá-los. Requer também os meios para realizar a mobilização. Essa visão, longe de desresponsabilizar o Estado, força que sejam buscadas soluções para o cumprimento do dever estatal de promover a participação social institucionalizada.

Com base na compreensão multidimensional de capacidades estatais desenvolvida neste artigo, reconhecida a deficiência em capacidades técnicas, a agência estatal com capacidade institucional e administrativa mobilizaria dentro ou fora do Estado os recursos cognitivos necessários para a realização da ação. Afinal, os recursos organizacionais necessários à preparação e realização de processos participativos podem ser mobilizados tanto na sociedade como no Estado. Assim, bastaria que existissem recursos institucionais, políticos e administrativos para que as condições para desenhar e desenvolver processos participativos pudessem existir.

Pela pesquisa realizada, foi possível perceber que as capacidades conversacionais necessárias à realização das conferências foram mobilizadas e não instaladas. Mesmo que pudessem existir os meios para a organização desses processos participativos, esses recursos não estavam disponíveis. Dessa forma, a utilização de recursos humanos contratados temporariamente mobilizou as capacidades técnicas necessárias ao desenho e desenvolvimento das metodologias nas conferências.

Esse trânsito de pessoas evidencia a noção das capacidades estatais como condições que podem estar disponíveis ou indisponíveis e assim mobilizadas. Essa constatação pode levar à sobrevalorização de agentes externos e desprestígio de agentes internos, isto é, tem-se a impressão de que não haveria corpo técnico capacitado para tais tarefas. O que, de fato, se verificou foi a indisponibilidade e não necessariamente inexistência. Ou seja, se servidores públicos poderiam aportar os conhecimentos técnicos necessários, eles não estavam alocados na função específica.

Como esta pesquisa deu voz apenas a integrantes de comissões organizadoras de conferências, não foi possível identificar se entre o restante do corpo funcional dos minis- 
térios existiam pessoas com conhecimentos que poderiam ter sido utilizados para dotar o Estado de capacidades conversacionais e que foram preteridos em relação às consultorias contratadas. Assim, não foi possível afirmar se a mobilização de capacidades conversacionais com a contratação de profissionais de fora do Estado é motivada pela inexistência de corpo técnico habilitado ou pela indisponibilidade desses recursos humanos originada, por exemplo, por ineficaz gestão de pessoas nas agências estatais. Também não se pode aferir, se a contratação de consultores se deu em função da identificação de uma ausência de capacidade técnica ou se ela se insere em um contexto de disputa sobre o modo de organização dos processos participativos. Assim, a contratação de consultorias poderia ocorrer para que as conferências fossem organizadas de um determinado jeito, por exemplo, desconsiderando as opiniões e habilidades de servidores do órgão responsável.

Se as capacidades estatais podem ser mobilizadas a depender das necessidades, é a combinação desses recursos o que gera as soluções metodológicas para os processos participativos. Ao identificar as capacidades estatais necessárias à promoção da participação e estudar a forma de mobilização das capacidades conversacionais, foi possível perceber que os recursos para a realização das conferências nacionais não estavam necessariamente instalados e assim foram mobilizados. Isso fez pensar as capacidades estatais não como atributos do aparato burocrático, mas sim como recursos mobilizáveis a depender das necessidades. Assim, é mais adequado o entendimento a respeito das capacidades estatais como recursos ou condições de ação que podem ser mobilizadas a depender das necessidades existentes e dos meios disponíveis ao Estado.

\section{Referências}

AVRITZER, Leonardo. A dinâmica da participação local no Brasil. São Paulo: Cortez, 2010.

Instituições participativas e desenho institucional: algumas considerações sobre a variação da participação no Brasil democrático. Opinião Pública, v.14, n. 1, p. 43-64, 2008.

; SOUZA, Clóvis Henrique Leite. Conferências Nacionais: entendendo a dinâmica da participação no nível nacional.In: AVRITZER, Leonardo; SOUZA, Clóvis Henrique Leite. (Org.). Conferências nacionais: atores, dinâmicas participativas e efetividades. Brasília: IPEA, 2013.

BAKER, Lynda Lieberman; FRASER, Cameron. Facilitator Core Competencies as Defined by the International Association of Facilitators. In: SCHUMAN, Sandy. (Ed.). The IAF Handbook of Group Facilitation. San Francisco: Jossey-Bass, 2005

BOJER, Marianne Mille et al. Mapeando diálogos: ferramentas essenciais para a mudança social. Rio de Janeiro: Instituto Noos, 2010.

BROWN, Juanita; ISAACS, David. O World Café: dando formas ao nosso futuro por meio de conversações significativas e estratégicas. São Paulo: Cultrix, 2007.

COTTA, Tereza Cristina. Burocracia, capacidade de Estado e mudança estrutural. Brasília: Enap, 1997. (Texto para Discussão 21).

EVANS, Peter. O Estado como problema e solução. Lua Nova, n. 28-29, São Paulo, abr. 1993. 
FARIA, Cláudia Feres. Sobre os determinantes das políticas participativas: a estrutura normativa e o desenho institucional dos conselhos. In: AVRITZER, Leonardo. (Org.). A participação social no Nordeste. Belo Horizonte: UFMG, 2007.

FORESTER, John. The Deliberative Practitioner: encouraging participatory planning processes. Cambridge: MIT Press, 1999.

GOMIDE,Alexandre de Ávila; PIRES, Roberto Rocha C. Capacidades Estatais e Democracia: arranjos institucionais de políticas públicas. Brasília: Ipea, 2014.

GRINDLE, Merilee Serrill. Challenging the State: crisis and innovation in Latin America and Africa. Cambridge: Cambridge University Press, 1996.

IPEA - Instituto de Pesquisa Econômica Aplicada. Ampliação da participação na gestão pública um estudo sobre conferências nacionais realizadas entre 2003 e 2011: Relatório de Pesquisa. Brasília: IPEA, 2013.

LAVALlE, Adrian Gurza; HOUTZAGER, Peter P.; CASTELlO, Graziela. Democracia, Pluralização da Representação e Sociedade Civil. Lua Nova, São Paulo, v. 67, n. 67, p. 49-103, 2006.

LEVITSKY, Steven; MURILLO, María Victoria. Variation in Institutional Strength. Annual Review of Political Science, n.. 12, p. 115-133, 2009.

MANN, Michael. A theory of the Modern State. The sources of social power:The Rise of Classes and Nation-States, 1760-1914, v. 2. Cambridge: Cambridge Press, 1993.

MAZZUCA, Sebastián L. Legitimidad, autonomía y capacidad: conceptualizando (una vez más) los poderes del Estado. Rev. cienc. polít. (Santiago), Santiago, v. 32, n. 3, p. 545-560, 2012.

MOSCOVICI, Serge; DOISE, Willem. Dissensões e consenso: uma teoria geral das decisões colectivas. Lisboa: Horizonte de Psicologia, 1991.

NASSUNO, Marianne. Burocracia e participação: a gestão no orçamento de Porto Alegre.Vinhedo: Editora Horizonte, 2011.

PEREIRA, Ana Karine. A construção de capacidade estatal por redes transversais: o caso de Belo Monte. 2014.264 f. Tese (Doutorado em Ciência Política) - Universidade de Brasília, Brasília 2014.

PIRES, Roberto Rocha Coelho. Efetividade das instituições participativas no Brasil: estratégias de avaliação. Brasília: IPEA, 2011.

PIRES, Roberto Rocha Coelho;VAZ, Alexander Cambraia Nascimento. Para além da participação: interfaces socioestatais no governo federal. Lua Nova, São Paulo n. 93, set./dez. 2014.

SOIFER, Hillel; HAU, Matthias vom. Unpacking the Strength of the State: The Utility of State Infrastructural Power. Studies in Comparative International Development, v. 43, p. 219-230, 2008.

SOUZA, Clóvis Henrique Leite de; PIRES, Roberto Rocha Coelho. Conferências Nacionais como Interfaces Socioestatais: seus usos e papéis na perspectiva de gestores federais. Revista do Serviço Público, Brasília, v. 63, n. 4, out./dez. 2012.

SOUZA, Luciana A. M. Afinal, o que é vontade política? Uma perspectiva a partir da comparação entre as variações dos resultados de experiências de orçamento participativo. In: ENCONTRO ANUAL DA ANPOCS, 37. , 2013, Águas de Lindoia. Anais... São Paulo: ANPOCS, 2013.

TOUCHTON, Michael; WAMPLER, Brian. Improving Social Well-Being Through New Democratic Institutions. Comparative Political Studies, p. 1-28, 2013. 


\title{
State capacities for promotion of participatory processes: attributes of the bureaucratic apparatus or temporary conditions for action?
}

\begin{abstract}
In proposing research on state capacities for the promotion of social participation, the study contributes with understanding about the organizational resources necessary for participatory public management, as well as investigating their form of mobilization. The investigative focus was on the state operation for the organization of national conferences. Thus, it revealed the importance of institutional, political and administrative capacities, enabling the identification of technical capacities that are linked to the design and development of participatory processes. The paper proposes the understanding that state capabilities are not necessarily attributes that can be installed in a structure, but rather conditions for action, organizational resources that can be mobilized. Thus, it allowed to review the understanding of capacities as attributes of a structure that can be generated or installed. With the research undertaken, it seems more reasonable to speak of state capabilities as resources that can be mobilized depending on needs.
\end{abstract}

Keywords: state capacities, social participation, national conferences.

\section{Capacidades estatales para la promoción de procesos participativos: ¿atributos del aparato burocrático o condiciones temporales para la acción?}

\section{Resumen}

Al proponer una investigación sobre las capacidades estatales para impulsar la participación social, el estudio contribuye para la comprensión de los recursos de la organización necesarios para la gestión participativa, además de investigar su forma de movilización. El enfoque de la investigación está en el ejercicio estatal para la organización de conferencias nacionales. De esa forma, reveló la importancia de las capacidades institucionales, políticas y administrativas, permitiendo la identificación de las capacidades técnicas que están vinculadas al diseño y desarrollo de procesos participativos. El artículo propone el entendimiento de que las capacidades del Estado no son necesariamente atributos que se pueden instalar en una estructura, sino al contrario, son condiciones para la acción y recursos de la organización que pueden ser movilizados. Por lo tanto, permitió revisar la comprensión de capacidades como atributos de una estructura que puede ser creada o instalado. Con la investigación emprendida, parece más razonable hablar de capacidades estatales como recursos que se pueden movilizar en función de las necesidades.

Palabras clave: capacidades estatales, participación social, conferencias nacionales. 